\title{
Anatomic feasibility of an endovascular valve-carrying conduit for the treatment of type A aortic dissection
}

Maximilian Kreibich, MD, ${ }^{\mathrm{a}, \mathrm{b}, \mathrm{c}}$ Tobias Soekeland, MS, ${ }^{\mathrm{a}, \mathrm{b}}$ Friedhelm Beyersdorf, MD, ${ }^{\mathrm{a}, \mathrm{b}}$

Joseph E. Bavaria, MD ${ }^{\mathrm{c}}$ Holger Schröfel, MD, ${ }^{\mathrm{a}, \mathrm{b}}$ Martin Czerny, MD, MBA,,${ }^{\mathrm{a}, \mathrm{b}}$ and Bartosz Rylski, MD ${ }^{\mathrm{a}, \mathrm{b}}$

\section{ABSTRACT}

Objective: The study objective was to screen patients with acute type A aortic dissection for anatomic feasibility of ascending aortic endovascular treatment with a valve-carrying conduit.

Methods: High-quality computed tomography scans of 167 patients were available for screening. Aortic dimensions were measured using multiplanar reconstruction in the plane perpendicular to the manually corrected aortic center line. The simulated stent-graft 10-mm-long landing zones were measured starting at the sinotubular junction (proximal landing zone) and ending at the brachiocephalic trunk (distal landing zone). Exclusion criterion was an entry within the aortic root or the landing zone.

Results: In 113 patients (68\%), the entry was in a coverable zone in the ascending aorta with sufficient proximal and distal landing zone or in more distal aortic segments. In these patients, the median distance between the proximal and distal landing zone was 89.1 (first quartile: $80.0 \mathrm{~mm}$; third quartile: $101.2 \mathrm{~mm}$ ) and the median diameter difference was $5.0 \mathrm{~mm}(2.0 ; 10.1)(12.3[4.9 ; 23.0] \%)$. The diameter difference was less than $2 \mathrm{~mm}$ in 32 patients $(28 \%)$, between 6 $\mathrm{mm}$ and $10 \mathrm{~mm}$ in 20 patients $(18 \%)$, between $10 \mathrm{~mm}$ and $14 \mathrm{~mm}$ in 11 patients $(10 \%)$, and $14 \mathrm{~mm}$ or greater in 10 patients $(9 \%)$.

Conclusions: Two thirds of all patients who present with type A dissections are potential candidates for treatment with endovascular valve-carrying conduits, but most patients would require tapered stent-grafts. (J Thorac Cardiovasc Surg 2019;157:26-34)

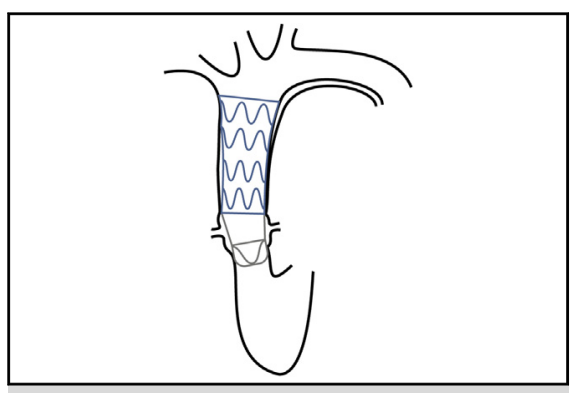

Treating a type A dissection with an endovascular valve-carrying conduit.

\section{Central Message}

An endovascular valve-carrying conduit may be a new treatment option for many patients with a type A aortic dissection.

\section{Perspective}

High-quality CT scans of 167 patients with type A aortic dissection were screened for the anatomic feasibility of ascending aortic endovascular treatment with a valve-carrying conduit. Two thirds of those patients are potential candidates for the treatment, but most patients would require tapered stent-grafts.

See Editorial Commentary page 35 .
Thoracic endovascular aortic repair (TEVAR) has significantly enriched the treatment options for diseases of the aorta and has become the treatment of choice for patients presenting with acute complicated type B dissections. ${ }^{1}$ However, there are only case reports and small case series

From the a Department of Cardiovascular Surgery, Heart Center University Freiburg, Freiburg, Germany; ${ }^{b}$ Faculty of Medicine, University of Freiburg, Freiburg, Germany; and ${ }^{\mathrm{c} D i v i s i o n}$ of Cardiovascular Surgery, Hospital of the University of Pennsylvania, Philadelphia, Pa.

Funding: Institutional funding.

Read at The American Association for Thoracic Surgery Aortic Symposium 2018 , New York, New York, April 26-27, 2018.

Received for publication March 8, 2018; revisions received May 7, 2018; accepted for publication May 8, 2018; available ahead of print July 3, 2018.

Address for reprints: Maximilian Kreibich, MD, Heart Center University Freiburg, Hugstetter Str 55, D-79106 Freiburg, Germany (E-mail: maximilian.kreibich@ universitaets-herzzentrum.de).

$0022-5223 / \$ 36.00$

Copyright (c) 2018 by The American Association for Thoracic Surgery

https://doi.org/10.1016/j.jtcvs.2018.05.045 regarding the use of TEVAR in patients presenting with type A aortic dissections, leaving the use of TEVAR in this setting experimental. ${ }^{2-5}$

Perioperative mortality after open surgical treatment for acute type A aortic dissection has reached a still significant plateau ranging from $10 \%$ to $20 \%,{ }^{6-10}$ whereas conservative treatment remains ineffective. ${ }^{11}$ Moreover, up to $8 \%$ of all patients presenting with an acute type $\mathrm{A}$ aortic dissection are deemed inoperable even in high-volume centers. ${ }^{12}$ TEVAR for patients with type A aortic dissection may present as an alternative to open

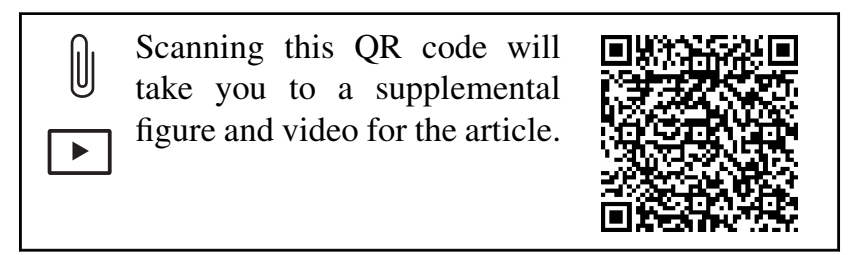




\section{Abbreviations and Acronyms}

$\mathrm{BCT}=$ brachiocephalic trunk

$\mathrm{CT}=$ computed tomography

$\mathrm{LZ}=$ landing zone

STJ = sinotubular junction

TEVAR $=$ thoracic endovascular aortic repair ascending aorta before the takeoff of the brachiocephalic trunk (BCT) for the sealing of the proximal and distal ascending aorta, respectively (Figure 1).

The aim of this study is to screen patients with acute type A aortic dissection for the anatomic feasibility of ascending aortic endovascular treatment with a valve-carrying conduit and to provide better insight into the anatomy of the dissected ascending aorta.

\section{PATIENTS AND METHODS \\ Patients}

Between 2004 and 2017, 395 patients underwent operation for type A aortic dissection at a single institution. Of those patients, electrocardiogramgated high-quality preoperative computed tomography (CT) scans were available in 167 patients who were included in this study. The institutional review committee approved this retrospective study, and the need for informed consent was waived.

\section{Imaging Analysis}

Aortic diameters and segmental lengths were analyzed according to electrocardiography-gated CT angiography. A slice thickness of $3 \mathrm{~mm}$ or less was accepted and present in all patients. Analysis was performed using 3mensio Vascular Version 7.2 (3mensio Pie Medical Imaging BV, Maastricht, The Netherlands). All measurements were taken in multiplanar reconstruction always in the plane perpendicular to the manually corrected local aortic centerline (Figure 2). Measurements of length were obtained along the centerline from the aortic annulus to both coronary arteries, to the STJ, to the entry in the ascending aorta, and to the supra-aortic vessels. In cases where the STJ was not definable, it was set $10 \mathrm{~mm}$ distally of the origin of the more distal coronary artery. Diameters were measured at the

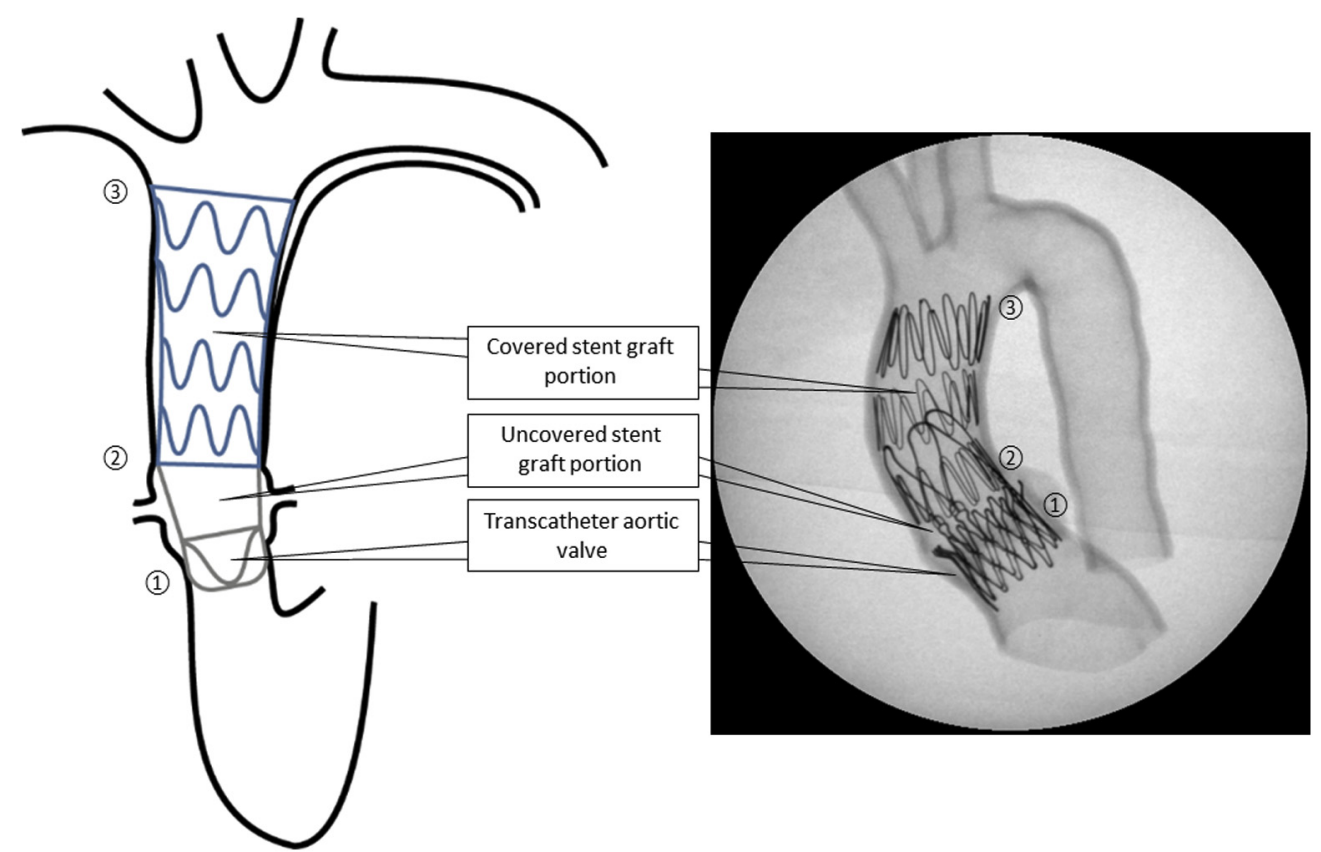

FIGURE 1. Schematic (left) and radiographic (right) depiction of the endovascular valve-carrying conduit within the dissected ascending aorta: Transapical catheter aortic valve replacement with implantation of the device in the aortic valve annulus (LZ (1) for stable anchorage of the device. The uncovered portion allows coronary perfusion and is connected to the covered stent-graft portion at the level of the proximal sealing LZ (2) at the STJ. The distal sealing LZ (3) is proximal to the offspring of the BCT. 


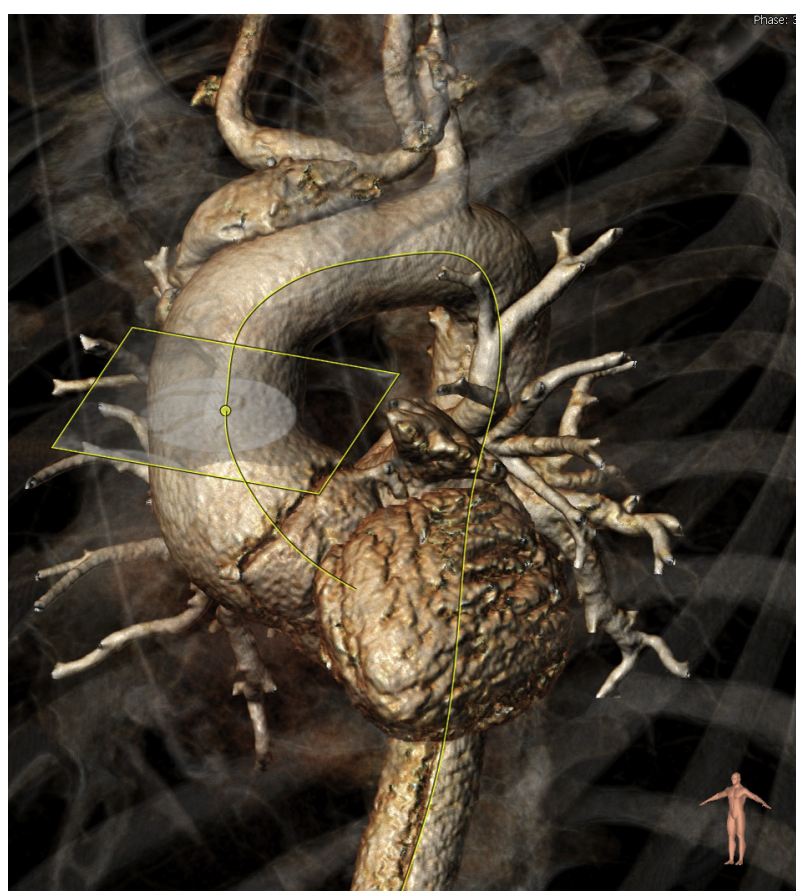

FIGURE 2. Representative 3-dimensional reconstruction of a dissected ascending aorta with the manually corrected local aortic centerline.

aforementioned anatomic landmarks and were calculated as the mean of the maximal and minimal diameter (Figure 3).

\section{Device Requirements}

The simulated stent-graft 10-mm-long LZ was measured starting at the STJ (proximal LZ) and ending at the BCT (distal LZ). Exclusion criterion was an entry within the aortic root or within the LZ. Aortic dimensions are summarized for all patients with anatomic feasibility for deployment of the device with the aforementioned exclusion criterion. Predissection aortic diameters were calculated according to the previously reported size increase at the STJ and the offspring of the BCT. ${ }^{14}$ A $5 \%$ oversizing regarding predissection diameter was defined for the stent-graft.

\section{Statistical Analysis}

All values are expressed as median (first quartile, third quartile) or as number (percentage).

\section{RESULTS}

\section{Entry Location}

The entry was in a coverable zone in the ascending aorta in 77 patients $(46 \%)$ and beyond the distal LZ in another 36 patients $(22 \%)$. Thus, deployment of the device would be possible in $113(68 \%)$ of all patients (Figure E1). Figure 4 provides an overview of the entry location in the ascending aorta and beyond.

\section{Aortic Length}

Aortic length characteristics are summarized in Table 1. The median distance from the aortic annulus to the STJ was $28.0(24.1 ; 30.0) \mathrm{mm}$ and $116.4(108.3 ; 128.1) \mathrm{mm}$ to the offspring of the BCT. The difference in length represents the median required stent-graft length of 89.1 (80.0; 101.2) $\mathrm{mm}$. Table 2 shows that $83 \%$ (93 patients) have a distance between 70 and $110 \mathrm{~mm}$ and that all patients can be categorized into 8 different length intervals of $10 \mathrm{~mm}$, respectively.

The aforementioned distance between the aortic annulus and the STJ of $28.0(24.1 ; 30.0) \mathrm{mm}$ also represents the distance between the first and the second LZ of the endovascular valve-carrying conduit and ranges from $20 \mathrm{~mm}$ (smallest distance) to $39.1 \mathrm{~mm}$ (maximal distance). The distances between the 2 zones are shown in Table 3, and the distance is more than $36 \mathrm{~mm}$ in 3 patients $(3 \% ; 36 \mathrm{~mm}$, $38 \mathrm{~mm}$, and $39.1 \mathrm{~mm}$ ).

\section{Aortic Diameter}

Table 4 shows the aortic diameters at the aortic annulus and the proximal and distal LZ. There is an absolute difference in the diameter between the STJ and the offspring of the BCT of $5.0(2.0 ; 10.1) \mathrm{mm}$ and a relative difference of $12.3(4.9 ; 23.0) \%$. The difference of diameter ranges from $0.2 \%$ to $275.2 \%$ in 1 patient, and the differences are depicted in Figure 5 for all patients. The diameter difference ( $\Delta$ ) was less than $2 \mathrm{~mm}$ in 32 patients $(28 \%), 2 \leq \Delta<6 \mathrm{~mm}$ in 40 patients $(35 \%), 6 \leq \Delta<10 \mathrm{~mm}$ in 20 patients $(18 \%)$, $10 \leq \Delta<14 \mathrm{~mm}$ in 11 patients $(10 \%)$, and $14 \mathrm{~mm}$ or greater in 10 patients $(9 \%)$.

\section{Aortic Root Dimensions}

The average diameter of the aortic annulus was 25.0 $(22.6 ; 27.1) \mathrm{mm}$. The smallest diameter of the aortic annulus was $17.5 \mathrm{~mm}$, and the largest diameter was $32.5 \mathrm{~mm}$. Only 1 patient $(1 \%)$ had a diameter less than $18 \mathrm{~mm}$, and in 7 patients $(6 \%)$, the diameter was more than $29 \mathrm{~mm}$. There is an absolute difference in the diameter between the aortic annulus and the calculated stent-graft diameter at the proximal LZ (STJ) of $11.5(8.1 ; 15.4) \mathrm{mm}$ and a relative difference of $47.1(34.3 ; 62.4) \%$.

The median distance from the aortic annulus to the left coronary artery was $17.0(14.0 ; 19.1) \mathrm{mm}$ and to the right coronary artery was $22.0(19.0 ; 24.1) \mathrm{mm}$. In 6 patients $(5 \%)$, the distance to the more proximal coronary artery was less than $10 \mathrm{~mm}$ : The distance to the left coronary artery was $5 \mathrm{~mm}$ in 2 patients, $8 \mathrm{~mm}$ in 1 patient, and $9 \mathrm{~mm}$ in 2 patients to the left coronary artery and in 1 patient to the right coronary artery.

\section{DISCUSSION}

The main findings of this study can be summarized as follows: (1) Up to $68 \%$ of all patients presenting with type A aortic dissection could benefit from an endovascular valvecarrying conduit; (2) 8 different stent-graft lengths (with 10$\mathrm{mm}$ intervals) would be required to treat all patients; (3) a substantial difference in diameters at the proximal and distal ascending aorta may require tapered stent-grafts in 


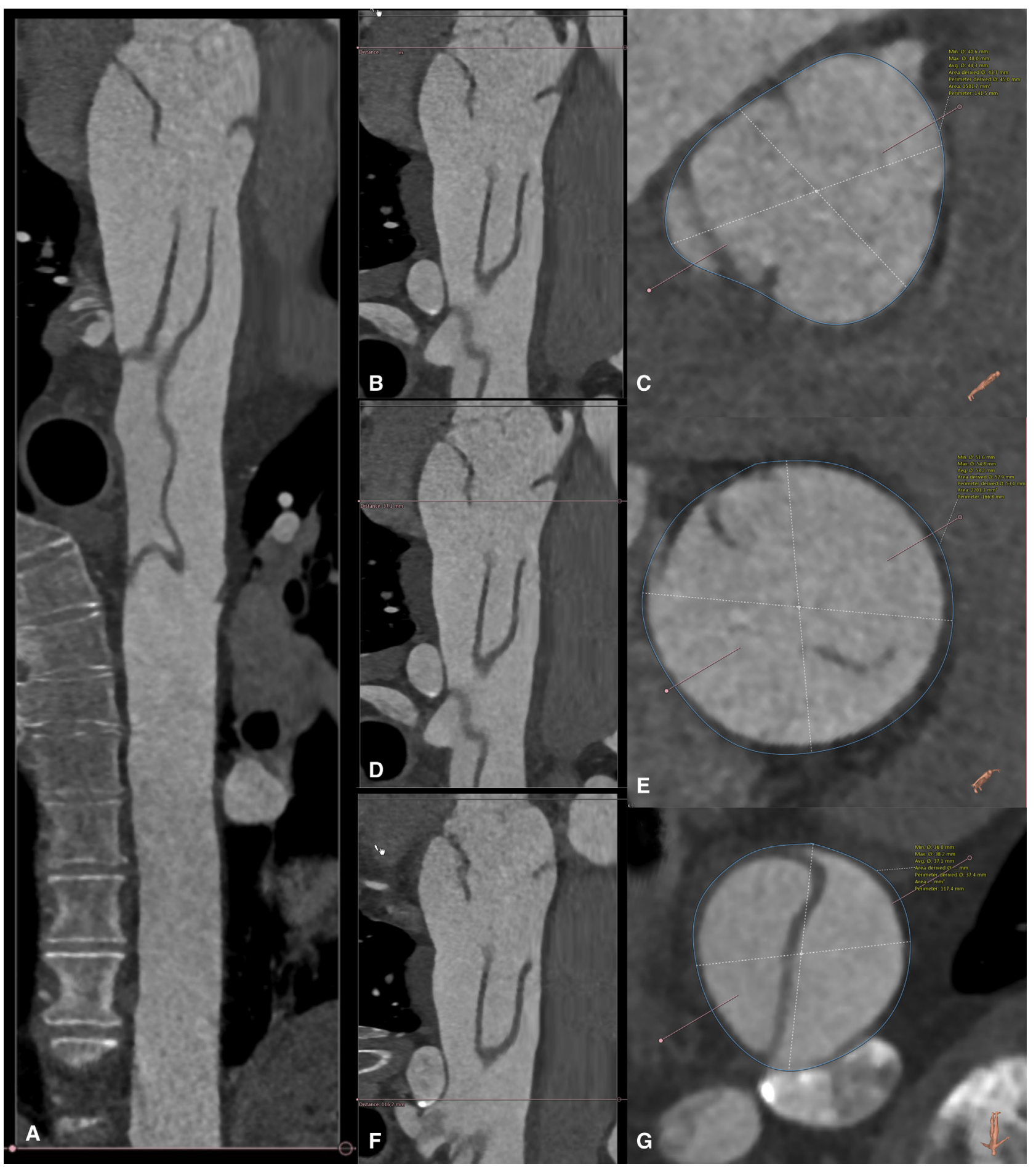

FIGURE 3. Representative measurements of length and aortic diameter in multiplanar reconstruction (A). Measurements were obtained along the centerline from the aortic annulus the coronary arteries (distance B, diameter C), to the STJ, to the entry in the ascending aorta (distance D, diameter E), and to the supra-aortic vessels (distance to BCT F, diameter G).

most patients; and (4) broader transcatheter aortic valve sizes would be required in $7 \%$ of the cases.

Endovascular treatment of acute type A aortic dissection is desirable but far from being standard treatment. ${ }^{2,3,12}$ The aim of TEVAR in the setting of acute dissection is to stabilize the aorta, to initialize false lumen thromboses and downstream remodeling, and to cause true lumen expansion by covering the primary entry and thereby also 


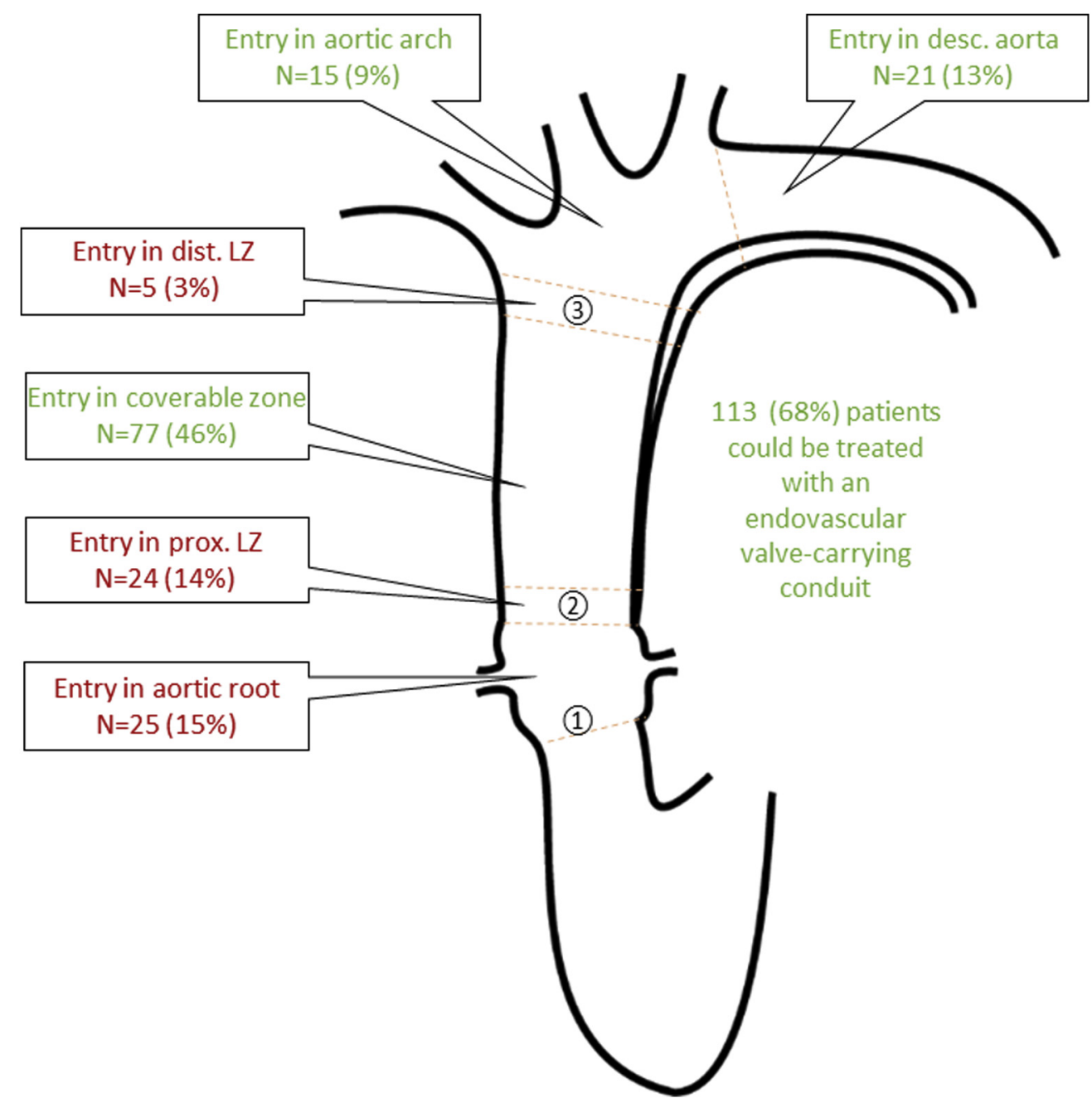

FIGURE 4. Schematic depiction of the location of the entry tears in the ascending aorta. LZ (1) is the aortic annulus for the catheter aortic valve. The simulated stent-graft 10-mm-long LZs were measured starting at the STJ (proximal LZ (2)) and ending at the BCT (distal LZ (3). Exclusion criterion for the implantation of an endovascular valve-carrying conduit was an entry within the aortic root or the LZ. Desc, Descending; dist., distal; LZ, landing zone; prox., proximal.

addressing the issue of distal malperfusion. ${ }^{15}$ In this study, $46 \%$ of all patients had an entry tear in a coverable zone in the ascending aorta. Another $22 \%$ of all patients developed retrograde type A dissection with an entry tear beyond the offspring of the BCT. In all those patients, the ascending aorta could be stabilized with an endovascular valve-

TABLE 1. Aortic length

\begin{tabular}{|c|c|c|c|}
\hline \multirow[b]{2}{*}{ Distance from aortic valve annulus } & \multirow[b]{2}{*}{ Median [first quartile; third quartile] } & \multicolumn{2}{|c|}{$\mathbf{N}=\mathbf{1 1 3}$} \\
\hline & & $\overline{\text { Minimum }}$ & Maximum \\
\hline To left coronary artery & $17.0[14.0 ; 19.1]$ & 5.0 & 30.1 \\
\hline To right coronary artery & $22.0[19.0 ; 24.1]$ & 9.0 & 31.0 \\
\hline To STJ & $28.0[24.1 ; 30.0]$ & 20.0 & 39.1 \\
\hline To beginning of dissection & $14.1[13.0 ; 23.1]$ & 2.0 & 108.4 \\
\hline To entry* & $65.2[48.0 ; 98.1]$ & 36.0 & 125.1 \\
\hline To BCT & $116.4[108.3 ; 128.1]$ & 78.4 & 150.1 \\
\hline Maximum stent-graft length $=$ distance STJ to BCT & $89.1[80.0 ; 101.2]$ & 55.3 & 122.3 \\
\hline Minimum stent-graft length $=$ distance STJ to entry $+10 \mathrm{~mm}^{\dagger}$ & $67.1[41.1 ; 84.2]$ & 22.0 & 106.3 \\
\hline
\end{tabular}

Values are in millimeters. STJ, Sinotubular junction; $B C T$, brachiocephalic trunk. *In ascending aorta $(\mathrm{n}=77)$. $\dagger$ To entry in ascending aorta $(\mathrm{n}=77)+10 \mathrm{~mm}$ or to BCT in case of entry in aortic arch $(n=15)$ or beyond $(n=21)$. 
TABLE 2. Tubular ascending aortic length

\begin{tabular}{lc}
\hline Distance from STJ to BCT & n (\%) \\
\hline $50-60 \mathrm{~mm}$ & $1(1)$ \\
$60-70 \mathrm{~mm}$ & $8(7)$ \\
\hline $70-80 \mathrm{~mm}$ & $19(17)$ \\
\hline $80-90 \mathrm{~mm}$ & $30(27)$ \\
\hline $90-100 \mathrm{~mm}$ & $23(20)$ \\
$100-110 \mathrm{~mm}$ & $21(19)$ \\
$110-120 \mathrm{~mm}$ & $9(8)$ \\
$120-130 \mathrm{~mm}$ & $2(2)$ \\
\hline
\end{tabular}

STJ, Sinotubular junction; $B C T$, brachiocephalic trunk.

carrying conduit as a temporary treatment solution (eg, in case of malperfusion and shock) or as a permanent solution.

The stability of the stent-graft position is limited in the ascending aorta because of the short length and the lack of healthy native aorta for a sufficient LZ. On the one hand, the ascending stent-graft should adequately stabilize the aortic media and seal the ascending entry. On the other hand, it must not result in the formation of new entry tears or aortic rupture in the proximal or distal LZ, and therefore oversizing should be limited to a minimum. Thus, we suggest adding a proximal LZ (Figure 1, (1) to the 2 stent-graft LZs (Figure 1, (2) and (3) by creating a valved conduit. The new proximal LZ (Figure 1, (1) would be generated by a transcatheter aortic valve that is connected to the stentgraft. Therefore, the transcatheter aortic valve at the level of the aortic annulus would be responsible for sufficient device stabilization. ${ }^{13}$ As a result, the proximal (Figure 1, (2)) and distal LZs (Figure 1, (3)) of the stent-graft no longer need to prevent stent-graft migration but only need to adequately seal and prevent persistent antegrade false lumen perfusion. Therefore, oversizing and LZ length can be limited. This may prevent or at least reduce the likelihood of progression of the dissection (eg, in the coronary arteries), aortic rupture, or creation of an endoleak compared

TABLE 3. Aortic root length

\begin{tabular}{lc}
\hline \multicolumn{1}{c}{$\begin{array}{c}\text { Distance from aortic } \\
\text { annulus to STJ }\end{array}$} & n (\%) \\
\hline $20-22 \mathrm{~mm}$ & $9(8)$ \\
$22-24 \mathrm{~mm}$ & $8(7)$ \\
\hline $24-26 \mathrm{~mm}$ & $21(19)$ \\
\hline $26-28 \mathrm{~mm}$ & $17(15)$ \\
\hline $28-30 \mathrm{~mm}$ & $25(22)$ \\
\hline $30-32 \mathrm{~mm}$ & $13(12)$ \\
\hline $32-34 \mathrm{~mm}$ & $10(9)$ \\
\hline $34-36 \mathrm{~mm}$ & $6(5)$ \\
\hline$\geq 36 \mathrm{~mm}$ & $3(3)$ \\
\hline STJ, Sinotubular junction.
\end{tabular}

STJ, Sinotubular junction. with a simple ascending stent-graft. Ideally, the stent-graft used in the ascending aorta should be more flexible than conventional stent-grafts with less radial force and shorter z-rings to enable a good stent-graft apposition in the curved ascending aorta.

The proximal portion of the stent-graft is uncovered and thereby allows coronary perfusion (Figure 1). However, there is a substantial diameter difference of approximately $50 \%$ between the aortic annulus and the proximal portion of the stent-graft at the STJ in addition to a variable length of the aortic sinus between 20 and $39.1 \mathrm{~mm}$. Thus, it seems plausible to allow complete individualization by choosing the aortic valve and the stent-graft separately. The 2 components can be connected individually and shortly before implantation with a suture or clips depending on the individual aortic measurements of the patient. The overlap of the components can be significantly shorter than the overlap of 2 conventional stent-grafts, because the 2 components are connected by sutures or clips.

Although isolated ascending aortic TEVAR would eliminate false lumen perfusion at least at the level of the stentgraft and cause true lumen expansion, it will not affect aortic regurgitation or influence cardiac tamponade. In fact, up to one third of all patients with ascending aortic dissection present with moderate to severe aortic regurgitation, and cardiac tamponade is common. ${ }^{7,16}$ By implanting an endovascular valve-carrying conduit from a transapical approach, both complications could be treated simultaneously. Moreover, a transapical approach would allow easy wire deployment in the true lumen. However, our data also show that $7 \%$ of the patients in this study had too small (1 patient) or too large (7 patients) aortic root diameters for currently available commercial transcatheter aortic valves (minimum annulus diameter for a $23-\mathrm{mm}$ transcatheter aortic valve: $18-20 \mathrm{~mm}$; maximum annulus diameter for a 31-mm transcatheter aortic valve: 26$29 \mathrm{~mm}) .{ }^{17}$ Thus, larger transcatheter aortic valves would be required to treat all patients with an endovascular valve-carrying conduit. Moreover, in 6 patients $(5 \%)$ the distance between the aortic annulus and the more proximal coronary artery was smaller than $10 \mathrm{~mm}$. The implantation of transcatheter aortic valves is possible in some patients with a distance less than $10 \mathrm{~mm}$ particularly in the absence of calcification, ${ }^{18}$ but our data suggest that the implantation of an endovascular valve-carrying conduit may be complicated in at least $5 \%$ of the patients because of the short distance to the coronary artery.

At the moment of dissection, a significant increase of the total aortic diameter can be observed, while the length of the aorta remains unaffected. ${ }^{14}$ Our data suggest that 8 stentgraft lengths would be sufficient to treat all patients with ascending aortic dissection. In fact, $83 \%$ of all patients could be treated with just 4 stent-graft lengths of $10-\mathrm{mm}$ intervals ranging from 70 to $100 \mathrm{~mm}$. However, our data also 
TABLE 4. Aortic diameter

\begin{tabular}{|c|c|c|c|}
\hline & \multirow[b]{2}{*}{ Median [first quartile; third quartile] } & \multicolumn{2}{|c|}{$\mathbf{N}=113$} \\
\hline & & Minimum & Maximum \\
\hline \multicolumn{4}{|l|}{ Diameter of dissected aorta } \\
\hline Diameter at STJ in mm & $40.8[34.6 ; 45.8]$ & 10.1 & 75.7 \\
\hline Diameter at $\mathrm{BCT}$ in $\mathrm{mm}$ & $42.8[37.9 ; 45.4]$ & 30.3 & 61.6 \\
\hline Difference STJ to BCT in $\mathrm{mm}$ & $5.0[2.0 ; 10.1]$ & 0.1 & 27.8 \\
\hline Difference in $\%$ & $12.3[4.9 ; 23.0]$ & 0.2 & 275.2 \\
\hline \multicolumn{4}{|l|}{ Calculated predissection diameter* } \\
\hline Diameter at STJ in $\mathrm{mm}$ & $35.1[29.8 ; 39.4]$ & 8.7 & 65.1 \\
\hline Diameter at $\mathrm{BCT}$ in $\mathrm{mm}$ & $36.0[31.8 ; 38.1]$ & 25.5 & 51.7 \\
\hline Difference STJ to BCT in $\mathrm{mm}$ & $4.2[1.6 ; 8.1]$ & 0.0 & 23.4 \\
\hline \multicolumn{4}{|l|}{ Stent-graft diameter $\dagger$} \\
\hline Diameter at STJ in mm & $36.8[31.2 ; 41.4]$ & 9.1 & 68.4 \\
\hline Diameter at BCT in mm & $37.7[33.4 ; 40.0]$ & 26.7 & 54.3 \\
\hline Difference STJ to BCT in $\mathrm{mm}$ & $4.4[1.6 ; 8.6]$ & 0.0 & 24.6 \\
\hline
\end{tabular}

Values are in millimeters. STJ, Sinotubular junction; $B C T$, brachiocephalic trunk. *As previously described by Rylski and colleagues. ${ }^{14} \dagger$ Oversizing of $5 \%$ according to calculated predissection diameter.

indicate a substantial difference in diameter between the proximal LZ (the STJ) and the distal LZ (10 mm proximal of the BCT offspring) of $12 \%$. Thus, tapered stent-grafts for the treatment of ascending aortic pathologies seem to be inevitable. A tapered stent-graft with a tolerance of maximum 2-mm aberration between a tapered stent-graft diameter and the aortic diameter would be sufficient for $91 \%$ of all patients $(28 \%$ would require a straight stentgraft, $35 \%$ would require a $4-\mathrm{mm}$ tapered stent-graft, $18 \%$ would require an $8-\mathrm{mm}$ tapered stent-graft, and $10 \%$ would require a $12-\mathrm{mm}$ tapered stent-graft). It remains unclear if patients with a substantial diameter difference of more than $14 \mathrm{~mm}$ can also be treated with a tapered stentgraft. Another solution would be the implantation of 2 stent-grafts with different diameters, but the short length of the ascending aorta seems to contradict this approach.

The concept of an endovascular valve-carrying conduit significantly increases the number of patients who are potential candidates for endovascular therapy for acute aortic dissection to $68 \%$. Even when excluding the $12 \%$ of patients who may not be treated with currently available transcatheter aortic valves ( $7 \%$ because of too small or too large annulus and $5 \%$ because of a limited distance between the annulus and the more proximal coronary artery), more than half of all patients would be potential candidates for endovascular treatment. In contrast, 2 high-quality anatomic feasibility studies for ascending aortic TEVAR in patients with type A aortic dissection identified just $31.5 \%{ }^{19}$ and $36.2 \%{ }^{20}$ of patients as potential candidates for an endovascular approach because patients were excluded in case of aortic regurgitation, inappropriate length and diameter of sealing regions, and a lack of a proximal LZ was the most common reason for exclusion. ${ }^{19-22}$ Thus, to treat more patients, it seems inevitable to reduce the length of the stent-grafts' LZs. However, without additional anchorage (eg, through a valved-conduit), this
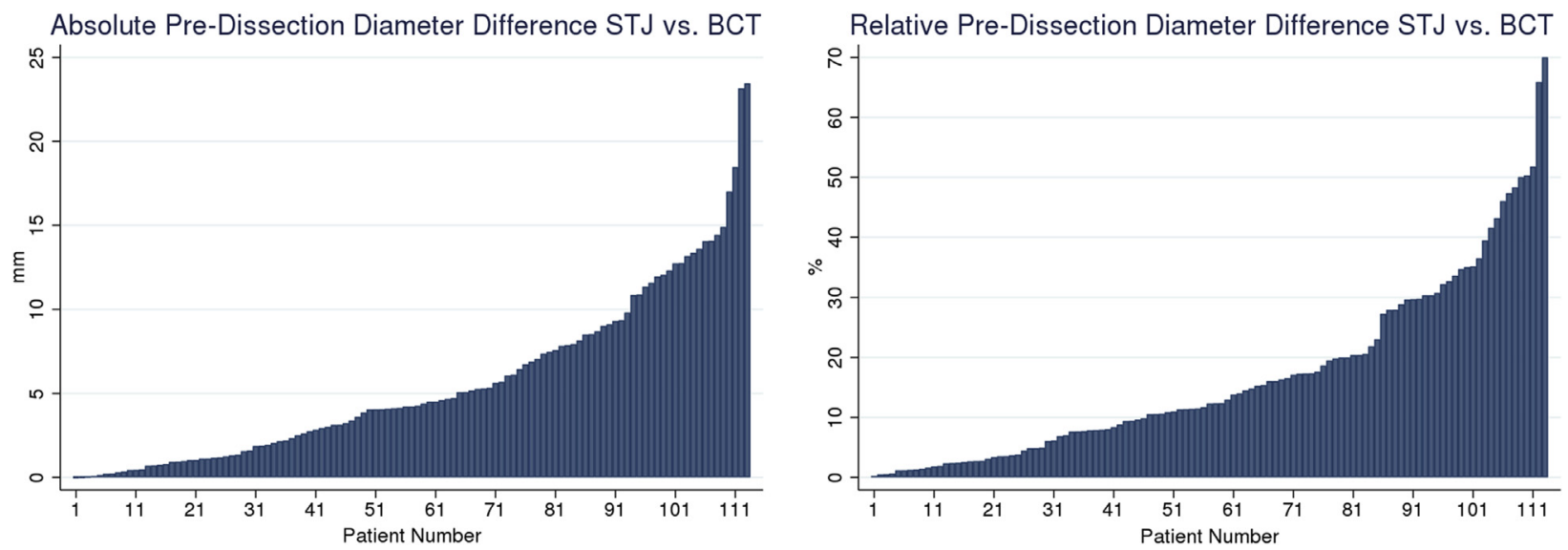

FIGURE 5. Absolute (left) and relative (right) diameter difference between the proximal LZ (STJ) and the distal LZ (before the offspring of the BCT). Note that patient 113 has a relative diameter difference of $275 \%$ that is not depicted. STJ, Sinotubular junction; BCT, brachiocephalic trunk. 


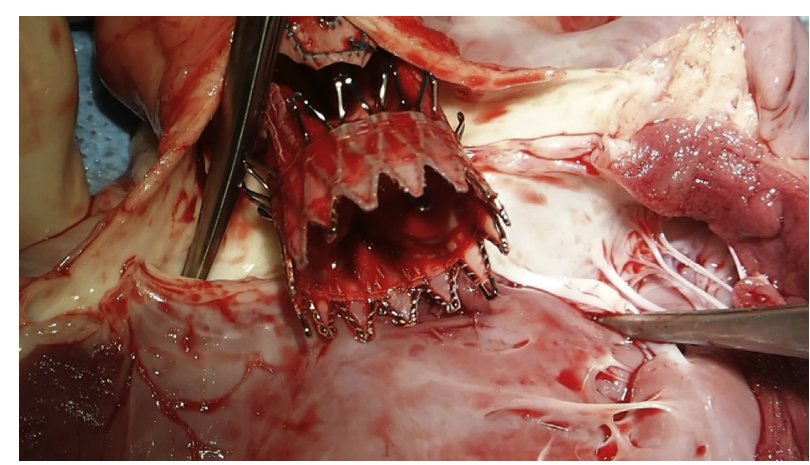

VIDEO 1. A video sequence depicts the transapical implantation of an endovascular valve-carrying conduit into the ascending aorta of a pig. The transcatheter aortic valve and the ascending aortic stent-graft are connected shortly before the implantation with sutures, and the 2 devices can be chosen individually (depending on the aortic annulus size and the ascending aortic length and diameter). The connected device is prepared for transapical access and successfully deployed. Three LZs are used: aortic annulus, STJ, and distal ascending aorta proximal to the offspring of the BCT. The uncovered portion between the transcatheter valve and the covered stentgraft allows coronary perfusion. Correct deployment was confirmed after animal euthanasia. Video available at: https://www.jtcvs.org/article/ S0022-5223(18)31467-3/fulltext.

may increase the risk for stent migration and endoleak development. Thus, a valved-conduit may increase the potential number of patients that may be treated endovascularly by decreasing the proximal and distal stent-grafts' LZ. The concept of an endovascular valve-carrying conduit is still experimental at this point (Video 1), but the fast, strong development and establishment of catheter-based therapies over the last decade has shown us that a new era of endovascular treatment has begun and that there is growing consideration of ascending endovascular treatment. $^{23,24}$

It is important to note that any endovascular treatment in the ascending aorta remains experimental ${ }^{2-5}$ and that it is not clear which patients would be ideal candidates for an ascending aorta first strategy. In addition, even in those patients, presumably elderly patients with shock or malperfusion, the patients' instability or the lack of highquality CT angiography scans (eg, performed in a referral hospital) might prevent adequate measurement of the CT angiography or prohibit repeat scanning. On the other hand, a hybrid operation room might facilitate sufficient imaging. In the ideal setting, the patient would be transferred from the outside hospital and the CT angiography images would be available online, and measurement of the annulus and LZ could be performed before the patient arrives. We would suggest a transapical approach, not only to resolve any cardiac tamponade but also to ensure correct wire placement in the true lumen. The transcatheter valve and the stent-graft would be chosen depending on the aortic measurements, connected, cropped, and implanted.
Depending on the location of the entry tear and the patient's condition, this could be a temporary treatment solution (eg, in case of malperfusion and entry in the aortic arch or the descending aorta) or a (semi-)permanent solution (in case of an entry tear in a coverable zone) requiring close follow-up. In any case, the valved conduit may be able to close any entry in the ascending aorta, initiate true lumen expansion, and thereby treat malperfusion, treat or prevent aortic regurgitation, drain any pericardial effusion, and stabilize the ascending aorta. Thus, any necessary complex open aortic surgery can be performed in a stable patient without distal malperfusion or shock. This also highlights the point that the treatment of the ascending aorta will remain a surgical domain not only to immediately address periprocedural complications but also to ensure later open surgical treatment when needed.

\section{Study Limitations and Strengths}

Although 228 patients could not be included in the study because of inadequate or unavailable high-quality imaging, our study collective of 167 patients is still one of the largest studies screening for anatomic feasibility for endovascular therapy and is the first to screen for treatment with a valve-carrying conduit. Also, we believe that the patient number is large enough to adequately describe the anatomy of the dissected ascending aorta. However, this study solely screened for anatomic feasibility of ascending aortic endovascular treatment with an endovascular valve-carrying conduit, and further research is necessary to illuminate the clinical practicability and safety of such devices. Nevertheless, it should be noted that these patients were screened purely on their radiographic imaging (ie, independent of age and other clinical factors). Therefore, it seems likely that although this study identified a relatively high number of potential candidates for endovascular treatment, clinically, this number is probably lower (ie, in case of very young patients).

\section{CONCLUSIONS}

Two thirds of all patients who present with type A dissections are potential candidates for endovascular treatment with valve-carrying conduits. This new therapeutic concept significantly increases the potential number of patients who are potential candidates for endovascular treatment of a type A dissection. Moreover, most patients who are candidates would require tapered stent-grafts.

\section{Conflict of Interest Statement}

Dr Bavaria reports an issued patent relevant to the work registered to the Trustees of the University of Pennsylvania (patent No. US 2015/0025625 A1). All other authors have nothing to disclose with regard to commercial support. 


\section{References}

1. Moulakakis KG, Mylonas SN, Dalainas I, Kakisis J, Kotsis T, Liapis CD. Management of complicated and uncomplicated acute type B dissection. A systematic review and meta-analysis. Ann Cardiothorac Surg. 2014;3:234-46.

2. Roselli EE, Brozzi N, Albacker T, Lytle BW. Transapical endovascular ascending repair for inoperable acute type a dissection. JACC Cardiovasc Interv. 2013;6: 425-6.

3. Preventza O, Henry MJ, Cheong BY, Coselli JS. Endovascular repair of the ascending aorta: when and how to implement the current technology. Ann Thorac Surg. 2014;97:1555-60.

4. Roselli EE, Idrees J, Greenberg RK, Johnston DR, Lytle BW. Endovascular stent grafting for ascending aorta repair in high-risk patients. J Thorac Cardiovasc Surg. 2015;149:144-51.

5. Petrov I, Stankov Z, Tasheva I, Stanilov P. Endovascular treatment of acute aortic dissection Stanford type A. JACC Cardiovasc Interv. 2018;11:218-9.

6. Hagan PG, Nienaber CA, Isselbacher EM, Bruckman D, Karavite DJ, Russman PL, et al. The international registry of acute aortic dissection (IRAD): new insights into an old disease. JAMA. 2000;283:897-903.

7. Rylski B, Bavaria JE, Milewski RK, Vallabhajosyula P, Moser W, Kremens E, et al. Long-term results of neomedia sinus Valsalva repair in 489 patients with type A aortic dissection. Ann Thorac Surg. 2014;98:582-9.

8. Rylski B, Beyersdorf F, Blanke P, Boos A, Hoffmann I, Dashkevich A, et al. Supracoronary ascending aortic replacement in patients with acute aortic dissection type A: what happens to the aortic root in the long run? J Thorac Cardiovasc Surg. 2013;146:285-90.

9. Dumfarth J, Kofler M, Stastny L, Plaikner M, Krapf C, Semsroth S, et al. Stroke after emergent surgery for acute type A aortic dissection: predictors, outcome and neurological recovery. Eur J Cardiothorac Surg. 2018;53:1013-20.

10. Larsen M, Trimarchi S, Patel HJ, Di Eusanio M, Greason KL, Peterson MD, et al Extended versus limited arch replacement in acute type A aortic dissection. Eur J Cardiothorac Surg. 2017:52:1104-10.

11. Dumfarth J, Peterss S, Luehr M, Etz CD, Schachner T, Kofler M, et al. Acute type A dissection in octogenarians: does emergency surgery impact in-hospital outcome or long-term survival? Eur J Cardiothorac Surg. 2017;51:472-7.

12. Roselli EE, Hasan SM, Idrees JJ, Aftab M, Eagleton MJ, Menon V, et al. Inoperable patients with acute type A dissection: are they candidates for endovascular repair? Interact Cardiovasc Thorac Surg. 2017;25:582-8.

13. Rylski B, Szeto WY, Bavaria JE, Branchetti E, Moser W, Milewski RK. Development of a single endovascular device for aortic valve replacement and ascending aortic repair. J Card Surg. 2014;29:371-6.
14. Rylski B, Blanke P, Beyersdorf F, Desai ND, Milewski RK, Siepe M, et al. How does the ascending aorta geometry change when it dissects? J Am Coll Cardiol. 2014;63:1311-9.

15. Rylski B. Endovascular repair of acute type A aortic dissection-we have the technology, but where is the courage? Interact Cardiovasc Thorac Surg. 2017;25: $501-2$.

16. Rylski B, Hoffmann I, Beyersdorf F, Suedkamp M, Siepe M, Nitsch B, et al. Acute aortic dissection type A: age-related management and outcomes reported in the German registry for acute aortic dissection type A (GERAADA) of over 2000 patients. Ann Surg. 2014;259:598-604.

17. Ussia GP, Sarkar K, Cammalleri V, Marchei M, Muscoli S, De Vico P, et al. Clinical results with the $31 \mathrm{~mm}$ CoreValve feminine in large aortic annuli: the importance of implantation technique. EuroIntervention. 2015;10:e1-8.

18. Ribeiro HB, Webb JG, Makkar RR, Cohen MG, Kapadia SR, Kodali S, et al. Predictive factors, management, and clinical outcomes of coronary obstruction following transcatheter aortic valve implantation: insights from a large multicenter registry. J Am Coll Cardiol. 2013;62:1552-62.

19. Moon MC, Greenberg RK, Morales JP, Martin Z, Lu Q, Dowdall JF, et al. Computed tomography-based anatomic characterization of proximal aortic dissection with consideration for endovascular candidacy. J Vasc Surg. 2011; 53:942-9.

20. Sobocinski J, O’Brien N, Maurel B, Bartoli M, Goueffic Y, Sassard T, et al. Endovascular approaches to acute aortic type A dissection: a CT-based feasibility study. Eur J Vasc Endovasc Surg. 2011;42:442-7.

21. Fujimura N, Kawaguchi S, Obara H, Yoshitake A, Inoue M, Otsubo S, et al. Anatomic feasibility of next-generation stent grafts for the management of type A aortic dissection in Japanese patients. Circ J. 2017;81:1388-94.

22. Huang C, Zhou M, Liu Z, Huang D, Ran F, Wang W, et al. Computed tomography-based study exploring the feasibility of endovascular treatment of type A aortic dissection in the Chinese population. J Endovasc Ther. 2014;21: 707-13.

23. Kubota H. Endovascular stent graft repair of the ascending aorta-final frontier in the endovascular treatment of the aorta. J Thorac Dis. 2016;8:E1358-60.

24. Horton JD, Kolbel T, Haulon S, Khoynezhad A, Green RM, Borger MA, et al. Endovascular repair of type A aortic dissection: current experience and technical considerations. Semin Thorac Cardiovasc Surg. 2016;28:312-7.

Key Words: ascending TEVAR, type A aortic dissection, valve-carrying conduit 


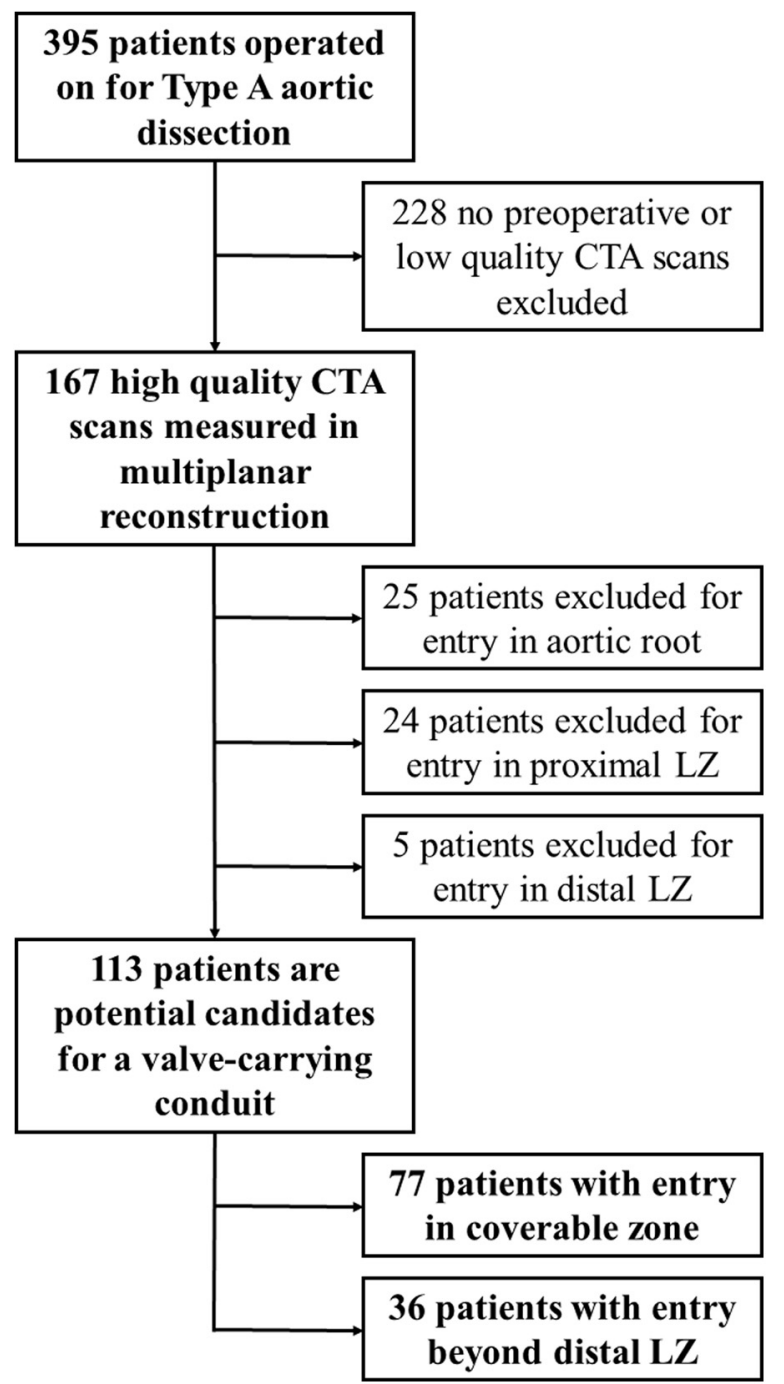

FIGURE E1. Illustrative flowchart. CTA, Computed tomography angiography; $L Z$, landing zone. 